\title{
Analysis and Optimization of Cutting Tool Coating Effects on Surface Roughness and Cutting Forces on Turning of AA 6061 Alloy
}

\author{
Mahir Akgün $\left.{ }^{1}\right)^{1}$ and Fuat Kara $\mathbb{D}^{2}$ \\ ${ }^{1}$ Department of Machine and Metal Technology, Aksaray University, Aksaray, Turkey \\ ${ }^{2}$ Department of Mechanical Engineering, Duzce University, Duzce, Turkey \\ Correspondence should be addressed to Fuat Kara; fuatkara@duzce.edu.tr
}

Received 18 August 2021; Revised 15 October 2021; Accepted 29 October 2021; Published 18 November 2021

Academic Editor: Tomasz Trzepieciński

Copyright (c) 2021 Mahir Akgün and Fuat Kara. This is an open access article distributed under the Creative Commons Attribution License, which permits unrestricted use, distribution, and reproduction in any medium, provided the original work is properly cited.

\begin{abstract}
The present work has been focused on cutting force $(\mathrm{Fc})$ and analysis of machined surface in turning of AA 6061 alloy with uncoated and PVD- $\mathrm{TiB}_{2}$ coated cutting inserts. Turning tests have been conducted on a CNC turning under dry cutting conditions based on Taguchi $\mathrm{L}_{18}\left(2^{1} \times 3^{3}\right)$ array. Kistler 9257A type dynamometer and equipment have been used in measuring the main cutting force $(\mathrm{Fc})$ in turning experiments. Analysis of variance (ANOVA) has been applied to define the effect levels of the turning parameters on Fc and Ra. Moreover, the mathematical models for Fc and Ra have been developed via linear and quadratic regression models. The results indicated that the best performance in terms of $\mathrm{Fc}$ and Ra was obtained at an uncoated insert, cutting speed of $350 \mathrm{~m} / \mathrm{min}$, feed rate of $0.1 \mathrm{~mm} / \mathrm{rev}$, and depth of cut of $1 \mathrm{~mm}$. Moreover, the feed rate is the most influential parameter on $\mathrm{Ra}$ and $\mathrm{Fc}$, with $64.28 \%$ and $54.9 \%$, respectively. The developed mathematical models for cutting force (Fc) and surface roughness $(\mathrm{Ra})$ present reliable results with coefficients of determination $\left(R^{2}\right)$ of $96.04 \%$ and $92.15 \%$, respectively.
\end{abstract}

\section{Introduction}

In our world, where global warming has been felt quite a lot in recent years, the need for intelligent methods and light materials is increasing. $\mathrm{CO}_{2}$ emission is an important criterion in terms of environmental pollution. The gaseous wastes of the environment are largely dependent on the $\mathrm{CO}_{2}$ emissions produced by the transport industry [1]. The use of lightweight materials for many automotive components is increasing in the automotive industry, where $\mathrm{CO}_{2}$ emissions are considered. Fuel savings are achieved by reducing weight by using light materials. An example of lightweight materials is the AA 6061 alloy. The main alloying element of this material is magnesium and silicon. Moreover, the density of this alloy of $2.63 \mathrm{~g} / \mathrm{cm}^{3}$ makes it important for applications where the strength-to-weight ratio is considered in the automotive, aircraft, and aerospace industries. AA 6061 alloy is also preferred more than other aluminium series because of their properties such as strength, formability, weldability, corrosion resistance, and low cost [2].
The desire to obtain products with high efficiency and quality in production sectors causes an increase in competitiveness. In this context, optimization techniques are used to improve the manufacturing process [3-7]. Especially with the optimization of the input parameters in machining, the costs can be reduced by saving time, energy consumption, and scrap. There are many studies in the literature on the Taguchi method, which is an optimization technique [8-10]. This method reduces production and testing costs by reducing the number of trials [11].

There are many studies on the determination of the machinability of different aluminium series in the literature. In their study, Rajeswari and Amirthagadeswaran machined a $7075 \mathrm{Al}$ material produced at different $\mathrm{SiC}$ reinforcement ratios on a milling machine. They investigated machining properties to obtain the minimum surface roughness, cutting force, tool wear, and maximum metal removal rate using RSM-based grey relational analysis in the spindle speed, feed rate, depth of cut, and material percentage weight 
ratios. Upon analyzing their results, optimum machining parameters were determined as a spindle speed of $1000 \mathrm{rpm}$, a feed rate of $0.03 \mathrm{~mm} / \mathrm{rev}$, a $1 \mathrm{~mm}$ depth of cut, and $\mathrm{SiC}$ ratio of $5 \%$ by weight [12]. Gonçalves and Silva investigated the effect of adding copper ( $\mathrm{Cu}$ ) AA 6351 (Al-Si-Mg) alloy at different ratios on workability and assessed the measurements of the drilling torque, compressive force, and surface roughness of the alloy during drilling. The cutting speeds and feed rates were examined according to five different values. Copper added into aluminium increased precipitation hardening. Drilling torque and compressive force increased linearly as the feed rate increased during drilling. Although higher drilling torque and compressive force were measured at the feed rate of $0.2 \mathrm{~mm} / \mathrm{rev}$ in drilling samples with increasing copper ratio, the surface roughness, on the other hand, worsened during drilling [13]. Demir and Gündüz examined the effect of artificial aging of $6061 \mathrm{Al}$ alloy on machinability and investigated the effect of different aging times and cutting speeds on cutting force and surface roughness at $180^{\circ} \mathrm{C}$. They determined that the aging time and the cutting speed both significantly affected the surface roughness values [2]. Ranganath et al. investigated the effect of cutting speed, feed rate, and depth of cut on surface roughness under dry cutting conditions of aluminium 6061 alloy. They determined that the most influential parameter on the surface roughness was the cutting speed. They obtained the lowest surface roughness value at the lowest depth of cut and feed rate, which were optimum levels of depth of cut [14]. Öztürk and Kara focused on calculating and estimating surface roughness and energy consumption in milling AA 6061 alloy. They reported that the surface roughness decreases as the energy consumption value during cutting increases for the spindle axis motor [15].

Literature survey indicated that there is considerable information relating to the machinability of aluminium alloys. However, it was observed that no extensive study was done into the surface roughness and cutting forces in turning AA 6061 alloy with different cutting tools. Therefore, this work aims to develop mathematical models of surface roughness $(\mathrm{Ra})$ and cutting forces $(\mathrm{Fc})$ in the turning AA 6061 alloy. In this context, turning tests have been carried out under dry cutting conditions on a CNC turning. The cutting forces that occurred in the experiments conducted under each cutting condition have been measured by a KISTLER 9257A piezoelectric dynamometer. In addition, the roughness of the machined surface has been measured after each experiment. The analysis of variance (ANOVA) has been applied to define the contribution of the turning parameters on the $\mathrm{Ra}$ and Fc. At the same time, regression analysis was performed to develop the prediction equations of $\mathrm{Ra}$ and Fc. Finally, for the estimation of Ra and Fc, linear and quadratic mathematical models have been developed and tested with a validation experiment.

\section{Experimental Methods}

2.1. Turning Process. The turning experiments were performed on CNC turning under dry cutting conditions. AA 6061 T6 alloy (to have a $50 \mathrm{~mm}$ diameter and a $300 \mathrm{~mm}$ length) was used as the workpiece material. The chemical composition of this material and its mechanical properties are given in Tables 1 and 2, respectively [2].

The uncoated and coated $\left(\mathrm{PVD}-\mathrm{TiB}_{2}\right)$ carbide cutting tools produced by Kennametal were used for the turning test and these insert qualities are KC5010 and K313, respectively. In addition, the geometries of cutting tools are ISO designation TCGT 16T304HP10. The entering angle of the cutting tool was $90^{\circ}$ and was mechanically fixed onto the tool holder under code STGCL 2020K16. Turning parameters and levels are given in Table 3.

\subsection{Surface Roughness and Cutting Force Measurement.} The surface roughness of the test samples was measured using the Mahr Perthometer M1 model test device. The cutoff length was $0.8 \mathrm{~mm}$ and the measurement length was $12 \mathrm{~mm}$. The surface roughness values were determined from measurements taken at three different points on the machined surfaces formed after each experiment. Then, the average surface roughness $(\mathrm{Ra})$ was determined by calculating the average of the measurements. Figure 1 shows the stages of the experimental setup.

The actual cutting force $\mathrm{Fz}(\mathrm{Fc})$, the feed rate $\mathrm{Fx}(\mathrm{Ff})$, and the radial force Fy (Fr), which served as the cutting force components during the turning experiments, were measured using a KISTLER 9257A type dynamometer and equipment. The cutting forces occurring during the machining of the samples were uploaded onto a computer via an RS-232C patch cord and the cutting forces were acquired in the form of plot using "DynoWare Type 2825Ai-2" software. Moreover, the tool wear mechanisms and types have been investigated at a Quanta FEG 250 scanning electron microscope (SEM).

2.3. Experimental Design and Optimisation. The turning tests were designed to define the ideal cutting parameters using Taguchi $\mathrm{L}_{18}\left(2^{1} \times 3^{2}\right)$ orthogonal array. $\mathrm{S} / \mathrm{N}$ ratio analysis was used to determine the levels of cutting parameters for the best machined surface and the lowest cutting force. Depending on the characteristic type, three methods are used for calculating the S/N ratios: "the nominal is the best," "larger is better," and "smaller is better" $[7,16,17]$. Since the smallest $\mathrm{Ra}$ and $\mathrm{Fc}$ values are requested, the equation corresponding to the "smaller is better" method given in equation (1) was used.

$$
\frac{S}{N}=-10 \log \left(\frac{1}{n} \sum_{i=1}^{n} y_{i}^{2}\right) .
$$

Analysis of variance (ANOVA) is applied to determine the impact of each input factor (Ct, Vc, $f$, and a) on Ra and Fc. Moreover, the linear and quadratic regression analysis has been used to develop the mathematical prediction equation of $\mathrm{Ra}$ and Fc. The purpose of this analysis is to numerically express the relationship between output ( $\mathrm{Ra}$ and $\mathrm{Fc}$ ) parameters and input $(\mathrm{Ct}, \mathrm{Vc}, f$, and a) parameters. Finally, the accuracy of the prediction equations and the 
TABLE 1: Chemical compositions of AA 6061 alloy.

\begin{tabular}{ccccccccrr}
\hline $\mathrm{Fe}$ & $\mathrm{Si}$ & $\mathrm{Cr}$ & $\mathrm{Mn}$ & $\mathrm{Mg}$ & $\mathrm{Zn}$ & $\mathrm{Cu}$ & $\mathrm{Ti}$ & $\mathrm{Others}$ & $\mathrm{Al}$ \\
\hline 0.5 & $0.6-1.0$ & 0.1 & $0.2-0.8$ & $0.8-1.2$ & 0.25 & $0.6-1.4$ & 0.1 & 0.15 & Kalan \\
\hline
\end{tabular}

TABle 2: Mechanical properties of AA 6061 alloy.

\begin{tabular}{lcccc}
\hline Temper & Yield strength $(\mathrm{MPa})$ & Tensile strength $(\mathrm{MPa})$ & Ductility (\% 50) & Hardness (Brinell) \\
\hline T6 & $240-270$ & $260-310$ & 20 & 95 \\
\hline
\end{tabular}

TABle 3: Turning parameters and levels.

\begin{tabular}{lcccc}
\hline Parameter & Symbol & Level I & Level II & Level III \\
\hline Cutting tools & $\mathrm{Ct}$ & Uncoated & Coated & 300 \\
Cutting speed $(\mathrm{m} / \mathrm{min})$ & $V c$ & 250 & 0.15 & 350 \\
Feed rate $(\mathrm{mm} / \mathrm{rev})$ & $f$ & 0.1 & 1.5 & 0.2 \\
Depth of cut $(\mathrm{mm})$ & $\mathrm{a}$ & 1 & 2 \\
\hline
\end{tabular}

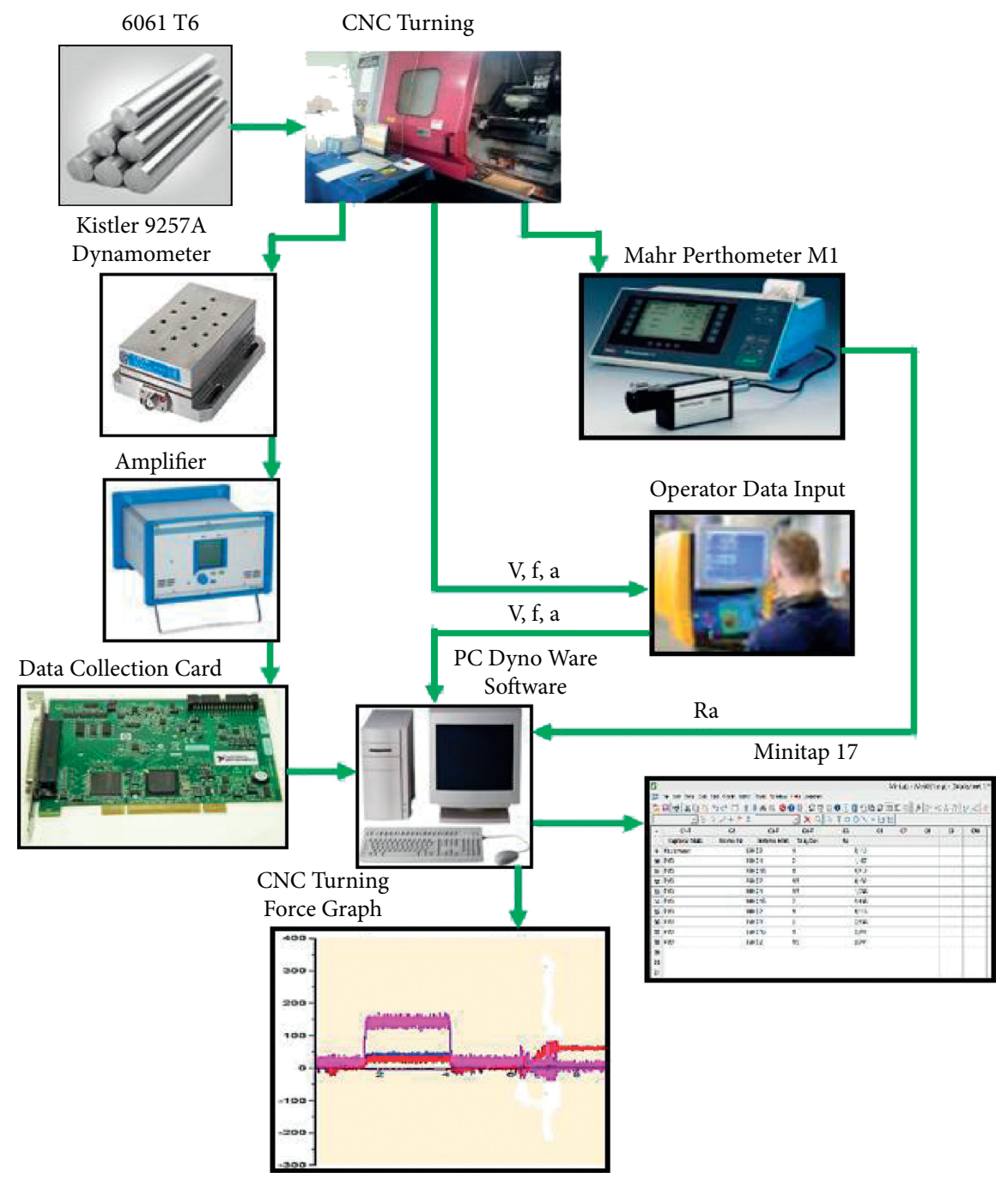

FIGURE 1: Experimental setup. 
system has been tried with confirmation tests accordingly to confidence interval (CI).

\section{Experimental Results and Discussion}

3.1. Analysis of the Signal-to-Noise $(S / N)$ Ratio. The $S / N$ response table was used for analysis of the influence of turning parameters on the Fc and Ra. Table 4 shows the $\mathrm{S} / \mathrm{N}$ ratios and the results of turning tests. Table 5 shows the ideal levels of turning parameters for the optimum Ra and Fc. The largest $\mathrm{S} / \mathrm{N}$ ratio for the smallest $\mathrm{Fc}$ and $\mathrm{Ra}$ values indicates the control factors being at optimum levels Figure 2 shows the graphs of $\mathrm{S} / \mathrm{N}$ ratios that were calculated for both the surface roughness $(\mathrm{Ra})$ and the cutting force $(\mathrm{Fc})$.

As a result of the cutting tests, the optimum surface roughness and cutting force values were found to be $0.387 \mu \mathrm{m}$ and $78.5 \mathrm{~N}$, according to Table 5 and Figure 2. Optimum results for surface roughness. The uncoated cutting tool was obtained at a cutting speed of $300 \mathrm{~m} / \mathrm{min}$, a feed rate of $0.1 \mathrm{~mm} / \mathrm{rev}$ and a depth of cut of $1 \mathrm{~mm}$. Optimum results for cutting force; The uncoated cutting tool was obtained at a cutting speed of $350 \mathrm{~m} /$ min, a feed rate of $0.1 \mathrm{~mm} / \mathrm{rev}$, and a depth of cut of $1 \mathrm{~mm}$.

3.2. Variance Analysis for $\mathrm{Ra}$ and $\mathrm{Fc}$. The variance analysis was utilized to analyze the effect of $\mathrm{Ct}, \mathrm{Vc}, f$, and a on $\mathrm{Ra}$ and Fc. This analysis was made with the confidence level of $95 \%$. Table 6 shows the variance analysis results for the actual cutting force $(\mathrm{Fc})$ and surface roughness values $(\mathrm{Ra})$. There are two important factors in this analysis. One is the $\mathrm{F}$ value while the other is the $(\mathrm{P})$ significance level. In order for each parameter to be meaningful on the results, the $P$ value is expected to be less than 0.05 , and also, the parameter with the largest $\mathrm{F}$ value is the most influential on the results $[7,18]$. Consequently, the most effective parameter affecting on both the surface roughness and cutting force was the feed rate with contribution of $64.28 \%$ and $54.9 \%$, respectively.

3.3. Experimental Results. Surface quality is considered for many applications in terms of dimensional accuracy, fatigue strength, wear resistance, and corrosion behavior. Therefore, the surface roughness is an important indicator for the machinability of engineering materials. The $\mathrm{Ra}$ graphs created according to the results of the turning tests performed to different cutting parameters with uncoated and $\mathrm{TiB}_{2}$ coated inserts are seen in Figure 3.

As can be seen from Figure 3, the surface roughness values are higher in the turning tests performed with the TiB 2 coated cutting tools than those done with the uncoated cutting tools. When both inserts are evaluated in terms of surface roughness, the surface roughness values are approximately 20-30\% more in turning tests performed with the coated cutting tools than the uncoated cutting tools. In machining ductile materials, it is expected that the cutting tools used have a positive rake angle and their edges are sharp. It is also recommended to use tools with chip breaker form $[19,20]$. It can be concluded that the coating reduces the depth of this chip breaker form in the tool geometry and therefore increases the surface roughness since the chip cannot be easily removed.
Moreover, it can be seen that the feed rate has a negative effect on surface roughness. The highest surface roughness values were measured at the highest level of the feed rate $(0.2 \mathrm{~mm} / \mathrm{rev})$. On the other hand, the surface roughness values slightly decrease depending on the increase in cutting speed. This can be explained by the decrease in the tendency of the chip to stick with increasing temperature in the cutting zone, depending on the increasing cutting speed [21]. Consequently, the lowest surface roughness value was measured as $0.387 \mu \mathrm{m}$ in the machining experiment performed with the uncoated tools in the cutting speed of $350 \mathrm{~m} / \mathrm{min}$, feed rate of $0.1 \mathrm{~mm} / \mathrm{rev}$, and depth of cut of $1 \mathrm{~mm}$.

The main cutting force $(\mathrm{Fc})$ values, which are of primary importance compared to other cutting force components (Ff and $\mathrm{Fp}$ ) in terms of energy consumption and machine tool dynamics and design, are taken into account. Figure 4 shows the variation in Fc with respect to cutting parameters.

When Figure 4 is examined, it can be seen that the Fc values increased with the increase in $f(\mathrm{~mm} / \mathrm{rev})$ on both cutting inserts. The Fc values are about 35\% increase with increasing feed rate from $0.1 \mathrm{~mm} / \mathrm{rev}$ to $0.15 \mathrm{~mm} / \mathrm{rev}$ while $47 \%$ increase by $f$ from $0.15 \mathrm{~mm} / \mathrm{rev}$ to $0.2 \mathrm{~mm} / \mathrm{rev}$ (Figure 5(a)). This situation is supported by the fact that the feed rate is the most effective parameter with $54.9 \%$ contribution rate according to the results of ANOVA analysis. This was associated with the need for more power in the chip removal process due to the increase in the chip cross-sectional area with the increase in the feed rate [22]. The increase in cutting force depending on the increase in feed rate and depth of cut is parallel to the studies in the literature [23-25].

Moreover, when the graps are examined, it is seen that the Fc values decreased with increasing cutting speed at all depths of cut and feed rates. The Fc values are about $30-45 \%$ decrease with increasing cutting speed from $250 \mathrm{~mm} / \mathrm{rev}$ to $300 \mathrm{~mm} / \mathrm{rev}$ while $50-65 \%$ decrease with increasing cutting speed from $300 \mathrm{~m} / \mathrm{min}$ to $350 \mathrm{~m} / \mathrm{min}$. In the literature, the tendency of built-up edge (BUE) formation is expected in the machining of ductile materials and it has been reported in many studies that it decreases with the increase in cutting speed and, consequently, the cutting force decreases [26]. The images of the uncoated and $\mathrm{TiB}_{2}$ coated cutting tools after machining at $250 \mathrm{~m} / \mathrm{min}, 300 \mathrm{~m} / \mathrm{min}$, and $350 \mathrm{~m} / \mathrm{min}$ obtained using scanning electron microscopy (SEM) are seen in Figure 5. Looking at the images in Figure 5, it is seen that BUE occurs in experiments performed at low cutting speeds and decreases with the increase in cutting speed. This formation on the cutting tool affects the surface roughness more than the cutting force, because the material adhering to the cutting tool causes scraping rather than cutting during the machining process, negatively affecting surface roughness and dimensional accuracy of a part or component [27].

3.4. Development of Regression Models for $R a$ and FC. The surface roughness and cutting force were modelled using linear and quadratic regression analysis. (2) and (3) show the estimation equations for $\mathrm{Ra}$ created using linear regression 
TABLE 4: Results of experiments and $\mathrm{S} / \mathrm{N}$ ratio values.

\begin{tabular}{|c|c|c|c|c|c|c|c|c|}
\hline \multirow[b]{2}{*}{ Test ID } & \multicolumn{4}{|c|}{ Control factors } & \multirow[b]{2}{*}{$\begin{array}{c}\text { Surface roughness } \\
\text { value, } \operatorname{Ra}(\mu \mathrm{m})\end{array}$} & \multirow[b]{2}{*}{$\begin{array}{l}\mathrm{S} / \mathrm{N} \text { ration for } \\
\mathrm{Ra}(\mathrm{dB})\end{array}$} & \multirow[b]{2}{*}{$\begin{array}{l}\text { Cutting force, } \\
\text { Fc (N) }\end{array}$} & \multirow[b]{2}{*}{$\mathrm{S} / \mathrm{N}$ for $\mathrm{Fc}(\mathrm{dB})$} \\
\hline & $\begin{array}{l}\text { A cutting tool } \\
(\mathrm{Ct})\end{array}$ & $\begin{array}{l}\text { B cutting } \\
\text { speed }(V c)\end{array}$ & $\begin{array}{l}\mathrm{C} \text { feed } \\
\text { rate }(f)\end{array}$ & $\begin{array}{l}\mathrm{D} \text { depth of } \\
\text { cut (a) }\end{array}$ & & & & \\
\hline 1 & Uncoated & 250 & 0.1 & 1 & 0.605 & 4.3648 & 87.2 & -38.8103 \\
\hline 2 & Uncoated & 250 & 0.15 & 1.5 & 1.127 & -1.0384 & 141.93 & -43.0415 \\
\hline 3 & Uncoated & 250 & 0.2 & 2 & 2.033 & -6.1627 & 213 & -46.5676 \\
\hline 4 & Uncoated & 300 & 0.1 & 1 & 0.46 & 6.7448 & 85.6 & -38.6495 \\
\hline 5 & Uncoated & 300 & 0.15 & 1.5 & 1.094 & -0.7803 & 140.63 & -42.9616 \\
\hline 6 & Uncoated & 300 & 0.2 & 2 & 1.978 & -5.9245 & 211.25 & -46.4959 \\
\hline 7 & Uncoated & 350 & 0.1 & 1.5 & 0.62 & 4.1521 & 105.99 & -40.5053 \\
\hline 8 & Uncoated & 350 & 0.15 & 2 & 1.364 & -2.6962 & 176.31 & -44.9255 \\
\hline 9 & Uncoated & 350 & 0.2 & 1 & 2.112 & -6.4938 & 130.53 & -42.3142 \\
\hline 10 & Coated & 250 & 0.1 & 2 & 1.167 & -1.3414 & 157.09 & -43.923 \\
\hline 11 & Coated & 250 & 0.15 & 1 & 2.213 & -6.8996 & 155.07 & -43.8106 \\
\hline 12 & Coated & 250 & 0.2 & 1.5 & 4.192 & -12.4484 & 236.91 & -47.4917 \\
\hline 13 & Coated & 300 & 0.1 & 1.5 & 1.058 & -0.4897 & 134.14 & -42.5512 \\
\hline 14 & Coated & 300 & 0.15 & 2 & 2.468 & -7.8469 & 211.57 & -46.5091 \\
\hline 15 & Coated & 300 & 0.2 & 1 & 4.115 & -12.2874 & 188.69 & -45.515 \\
\hline 16 & Coated & 350 & 0.1 & 2 & 0.868 & 1.2296 & 151.67 & -43.618 \\
\hline 17 & Coated & 350 & 0.15 & 1 & 2.241 & -7.0088 & 148.75 & -43.4491 \\
\hline 18 & Coated & 350 & 0.2 & 1.5 & 3.944 & -11.9187 & 224.12 & -47.0096 \\
\hline
\end{tabular}

TABLe 5: S/N response table for Ra and Fc.

\begin{tabular}{|c|c|c|c|c|}
\hline & \multicolumn{4}{|c|}{ Control factors } \\
\hline & A & $\mathrm{B}$ & $\mathrm{C}$ & $\mathrm{D}$ \\
\hline \multicolumn{5}{|l|}{$R a$} \\
\hline 1 & -0.8705 & -3.9210 & 2.4434 & -3.5967 \\
\hline 2 & -6.5568 & -3.7893 & -4.3784 & -3.7539 \\
\hline 3 & - & -3.4307 & -9.2060 & -3.7904 \\
\hline Delta & 5.6863 & 0.4903 & 11.6493 & 0.1937 \\
\hline \multicolumn{5}{|l|}{$F c$} \\
\hline 1 & -42.70 & -43.94 & -41.34 & -42.09 \\
\hline 2 & -44.88 & -43.78 & -44.12 & -43.93 \\
\hline 3 & - & -43.64 & -45.90 & -45.34 \\
\hline Delta & 2.18 & 0.30 & 4.56 & 3.25 \\
\hline
\end{tabular}

The bold numbers in the table indicate the most effective level.

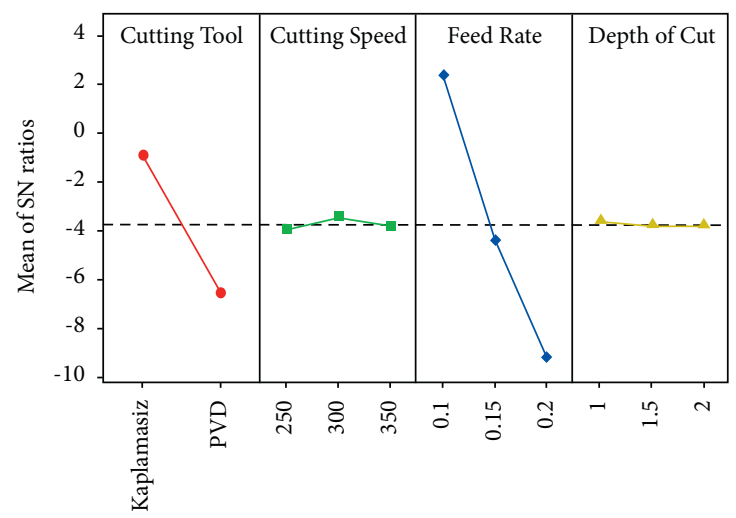

Signal-to-noise: Smaller is better

(a)

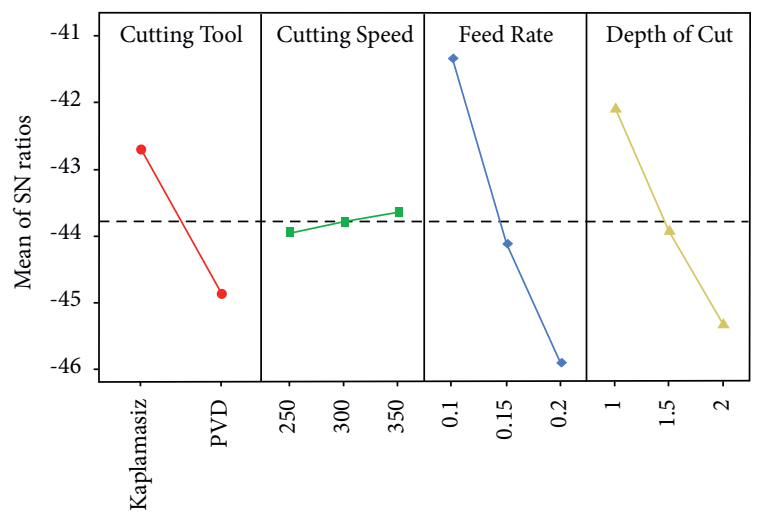

Signal-to-noise: Smaller is better

(b)

Figure 2: Main effects plot of $\mathrm{S} / \mathrm{N}$ ratios for $\mathrm{Ra}$ (a) and $\mathrm{Fc}$ (b). 
and quadratic models, respectively, while (4) and (5) show the estimation equations for $\mathrm{Fc}$ created using linear regression and quadratic models, respectively. The correlation coefficients $\left(R^{2}\right)$ of equations (2) and (3) for Ra are $92.15 \%$ and $99.63 \%$ while the correlation coefficients $\left(R^{2}\right)$ of equations (4) and (5) for $\mathrm{Fc}$ are $96.4 \%$ and $99.91 \%$. Consequently, the high ratio of the correlation coefficient $\left(R^{2}\right)$ indicates that the relationship between dependent and independent variables is quite strong. Therefore, the linear and quadratic regression models were accepted ideally for the prediction of $\mathrm{Ra}$ and Fc. Moreover, the prediction equations developed for $\mathrm{Ra}$ and $\mathrm{Fc}$ were checked by verification tests. The comparisons of estimated values with experimental results for Ra and Fc are given in Figures 6 and 7 , respectively.

$$
\begin{aligned}
R a= & -2.78+1.208 C t-0.00031 V c+22.66 f-0.311 a \\
R a_{q}= & 0.75-0.807 C t+0.003 V c-26.5 f+0.73 a-0.000001 V c^{2}+70.2 f^{2}+0.053 a^{2}-0.00227 C t V c \\
& +18.06 C t f-0.034 C t a+0.0139 V c f-0.00113 V c a-2.27 f a \\
F c= & -66.5+35.06 C t-0.0897 V c+804.7 f+54,18 a \\
F c_{q}= & 46.5+20.2 C t-0.207 V c+7 f-1.4 a+0.000449 V c^{2}-595 f^{2}-0.65 a^{2}-0.0796 C t V c+313.9 C t f \\
& -1.34 C t a-0.224 V c f+0.0327 V c a+382.1 f a .
\end{aligned}
$$

3.5. Verification Tests. The final step of the optimization process is to test the validity of the optimization. In this context, it is necessary to determine the confidence interval for the accuracy of the optimum cutting parameters determined by the Taguchi method. Firstly, (6) and (7) have been used, respectively, to calculate Fc and Ra values at the optimum cutting factor levels.

$$
\begin{aligned}
& F c_{\text {opt }}=\left(A_{1}-T_{\mathrm{Fc}}\right)+\left(B_{3}-T_{\mathrm{Fc}}\right)+\left(C_{1}-T_{\mathrm{Fc}}\right)+\left(D_{1}-T_{\mathrm{Fc}}\right)+T_{\mathrm{Fc}}, \\
& \mathrm{Ra}_{\text {opt }}=\left(A_{1}-T_{\mathrm{Ra}}\right)+\left(B_{3}-T_{\mathrm{Ra}}\right)+\left(C_{1}-T_{\mathrm{Ra}}\right)+\left(D_{1}-T_{\mathrm{Ra}}\right)+T_{\mathrm{Ra}} .
\end{aligned}
$$

$T_{\mathrm{Fc}}(161.136 \mathrm{~N})$ and $T_{\mathrm{Ra}}(1.869 \mu \mathrm{m})$ values are the average of the $\mathrm{Fc}$ and $\mathrm{Ra}$ values measured as a result of 18 experiments. As a result, the Fc and Ra values have been calculated to be $69.292 \mathrm{~N}$ and $0.403 \mu \mathrm{m}$, respectively. In the second step, the confidence interval (CI) was calculated using the equations (8) and (9). The representations of the expression equations (8) and (9) are given in Table 7. For equation (10), F0.05, 1, $10=4.9646$ (from $\mathrm{F}$ test table), $V e_{F c}=131.2$ and $V e_{R a}=0.16019$ (Table 5), $R=1, N=18$, $T_{\text {do } f}=7$, and $n_{\text {eff }}=2.25$ (equation (11)).

$$
\begin{aligned}
\mathrm{CI} & =\sqrt{F_{a, 1, f e} V_{e}\left[\frac{1}{n_{\mathrm{eff}}}+\frac{1}{R}\right]}, \\
n_{\mathrm{eff}} & =\frac{N}{1+T_{\mathrm{dof}}} .
\end{aligned}
$$

$\mathrm{CI}_{\mathrm{Fc}}$ and $\mathrm{CI}_{\mathrm{Ra}}$ are obtained as 46 and 1.607 by using (10), respectively.

$$
\begin{aligned}
{\left[\mathrm{Fc}_{\mathrm{opt}}-\mathrm{CI}_{\mathrm{Fc}}\right]<\mathrm{Fc}_{\exp }<\left[\mathrm{Fc}_{\mathrm{opt}}+\mathrm{CI}_{\mathrm{Fc}}\right] } & =69.292-46<78.5<[69.292+46] \\
& =23.292<78.5<115.292, \\
{\left[\mathrm{Ra}_{\mathrm{opt}}-\mathrm{CI}_{\mathrm{Ra}}\right]<\mathrm{Ra}_{\exp }<\left[\mathrm{Ra}_{\mathrm{opt}}+\mathrm{CI}_{\mathrm{Ra}}\right] } & =0.403-1.607<0.387<[0.403+1.607] \\
& =-1.204<0.387<2.01 .
\end{aligned}
$$

At the last stage, since the $\mathrm{Fc}$ and $\mathrm{Ra}$ are determined within the confidence interval limit in (10) and (11), the optimization process is completed successfully with the
Taguchi method at a 95\% significance level. The deviations between the actual and predicted values obtained in the cutting level groups for Fc and Ra are given in Figure 8. 
TABLE 6: Results of ANOVA for Ra and Fc.

\begin{tabular}{|c|c|c|c|c|c|c|}
\hline Variance & Degree of freedom (DoF) & Sum of squares (SS) & Mean square (MS) & $F$ ratio & $P$ ratio & Contribution rate (\%) \\
\hline \multicolumn{7}{|l|}{$R a$} \\
\hline $\mathrm{Ct}$ & 1 & 6.5679 & 6.56790 & 41.00 & 0.000 & 27.18 \\
\hline$V c$ & 2 & 0.0035 & 0.00174 & 0.01 & 0.989 & 0.014 \\
\hline$f$ & 2 & 15.5312 & 7.76562 & 48.48 & 0.000 & 64.28 \\
\hline a & 2 & 0.4570 & 0.22849 & 1.43 & 0.285 & 1.89 \\
\hline Error & 10 & 1.6019 & 0.16019 & - & - & 6.62 \\
\hline Total & 17 & 24.1615 & & & & 100 \\
\hline \multicolumn{7}{|l|}{$F c$} \\
\hline $\mathrm{Ct}$ & 1 & 5532.5 & 5532.5 & 42.18 & 0.000 & 15.62 \\
\hline$V c$ & 2 & 247.9 & 123.9 & 0.95 & 0.421 & 0.7 \\
\hline$f$ & 2 & 19439.3 & 9719.7 & 74.11 & 0.000 & 54.9 \\
\hline a & 2 & 8876.2 & 4438.1 & 33.84 & 0.000 & 25.06 \\
\hline Error & 10 & 1311.5 & 131.2 & - & - & 3.7 \\
\hline Total & 17 & 35407.4 & & & & 100 \\
\hline
\end{tabular}

The bold numbers in the table indicate the most effective parameters.

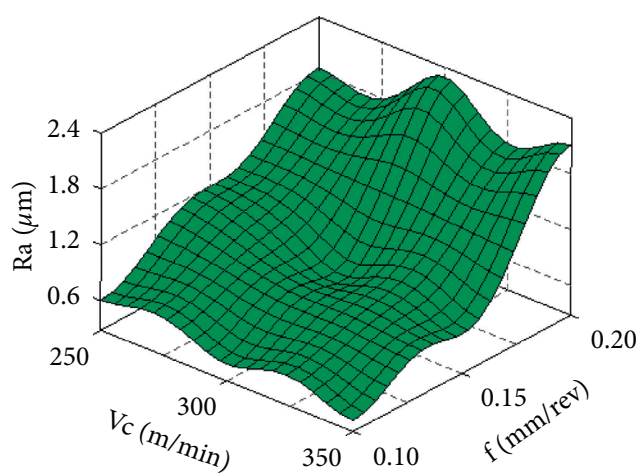

(a)

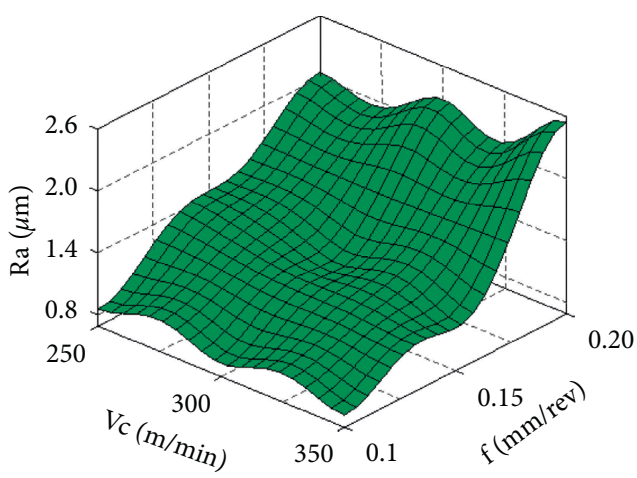

(c)

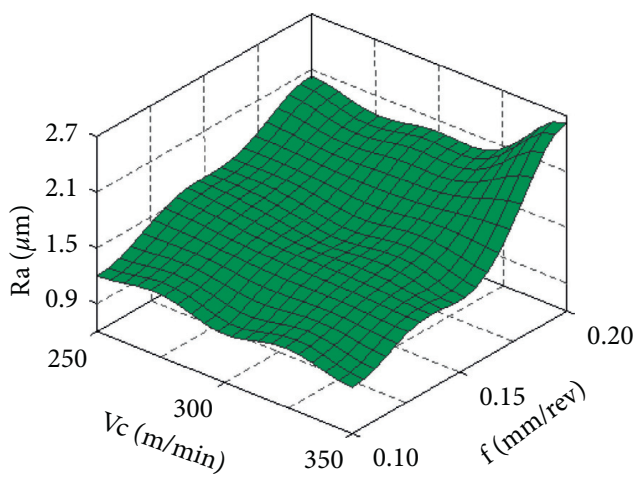

(e)

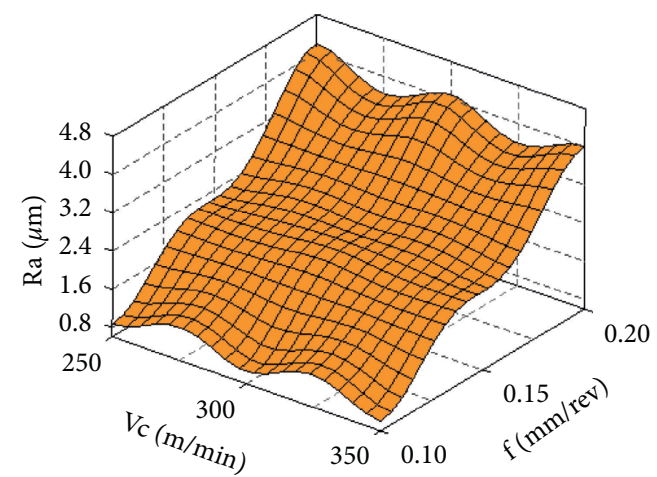

(b)

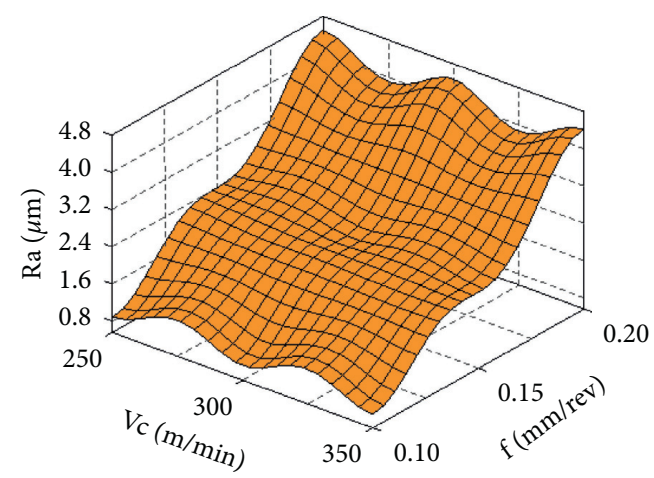

(d)

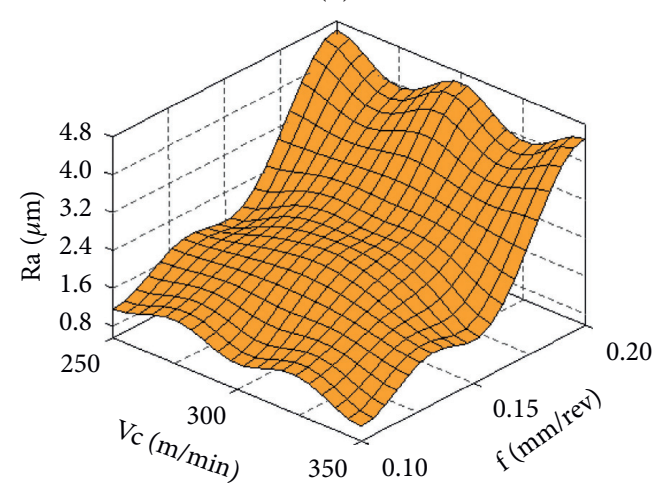

(f)

FIGURE 3: Effects of machining parameters on Ra. (a) Uncoated insert $/ \mathrm{a}=1 \mathrm{~mm}$; (b) TiB2 coated insert/a=1 mm; (c) uncoated insert/ $\mathrm{a}=1.5 \mathrm{~mm}$; (d) TiB2 coated insert $/ \mathrm{a}=1.5 \mathrm{~mm}$; (e) uncoated insert $/ \mathrm{a}=2 \mathrm{~mm}$; (f) TiB2 coated insert $/ \mathrm{a}=2 \mathrm{~mm}$. 

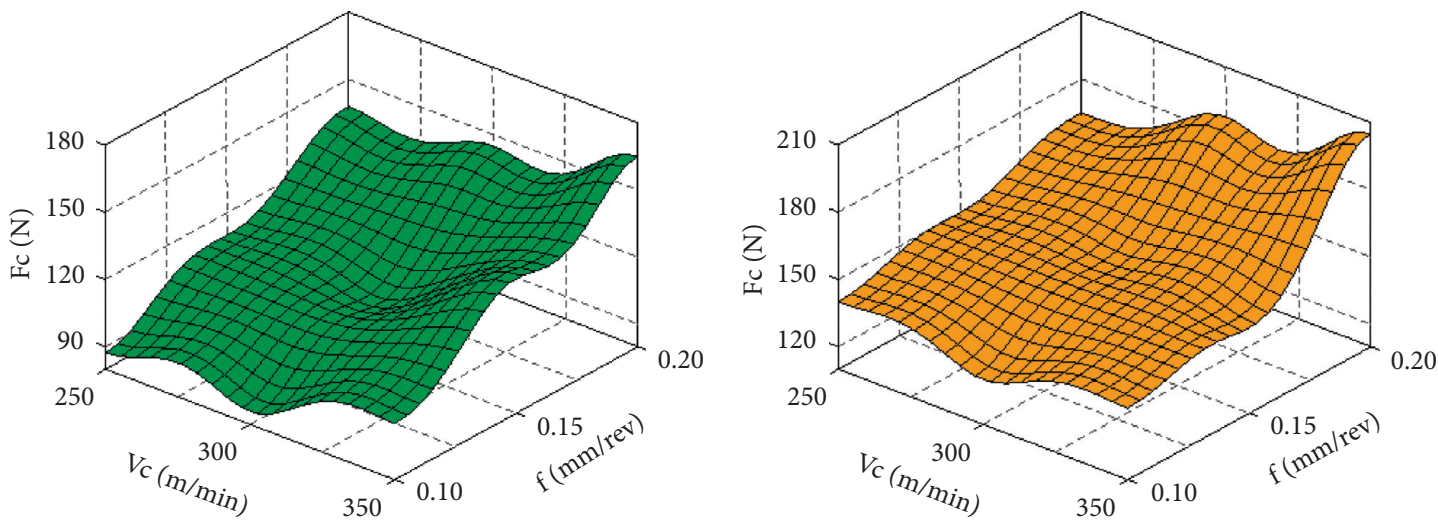

(a)

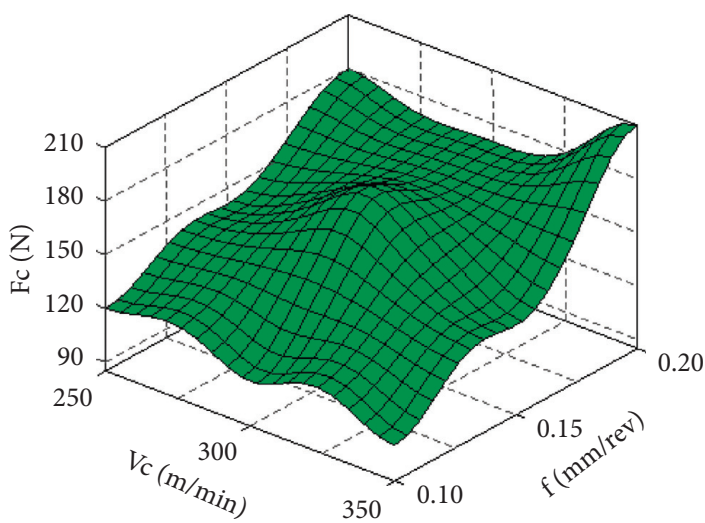

(c)

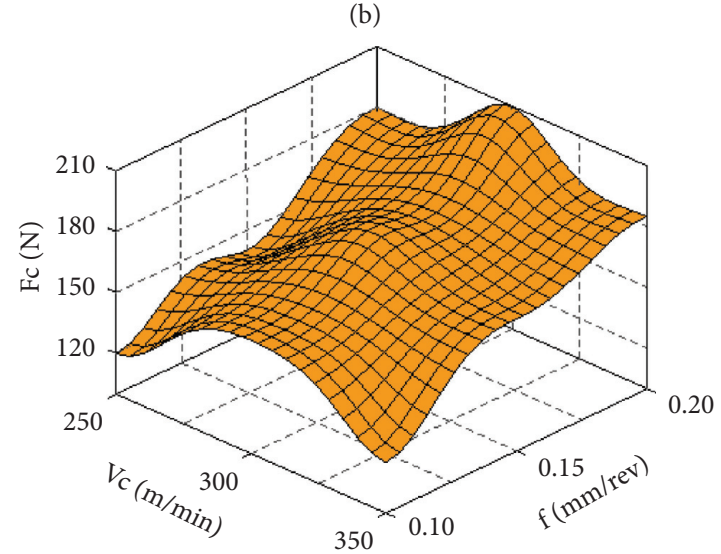

(d)

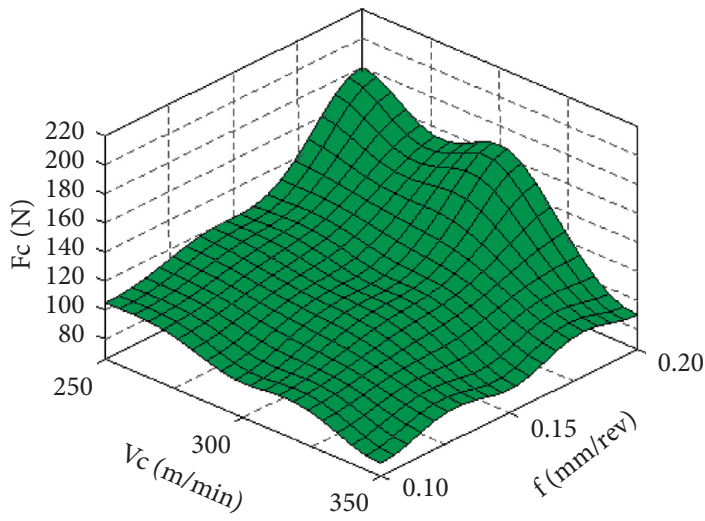

(e)

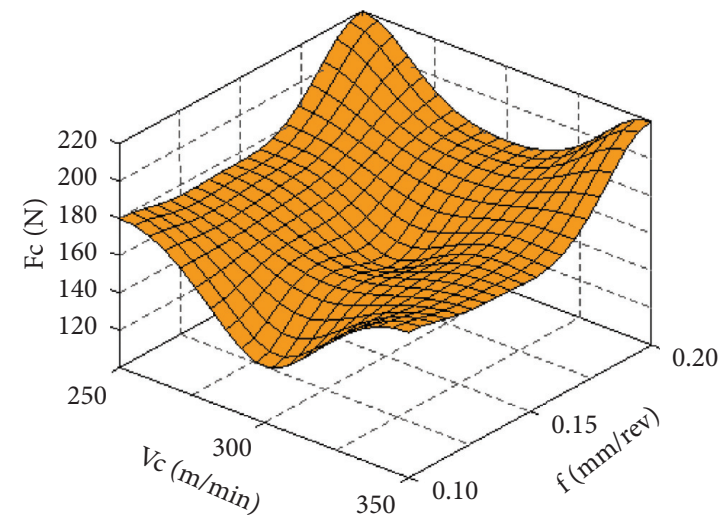

(f)

FIgURE 4: Effects of machining parameters on Fc. (a) Uncoated insert $/ \mathrm{a}=1 \mathrm{~mm}$; (b) TiB2 coated insert/a=1 mm; (c) uncoated insert/ $\mathrm{a}=1.5 \mathrm{~mm}$; (d) TiB2 coated insert $/ \mathrm{a}=1.5 \mathrm{~mm}$; (e) uncoated insert $/ \mathrm{a}=2 \mathrm{~mm}$; (f) TiB2 coated insert $/ \mathrm{a}=2 \mathrm{~mm}$.

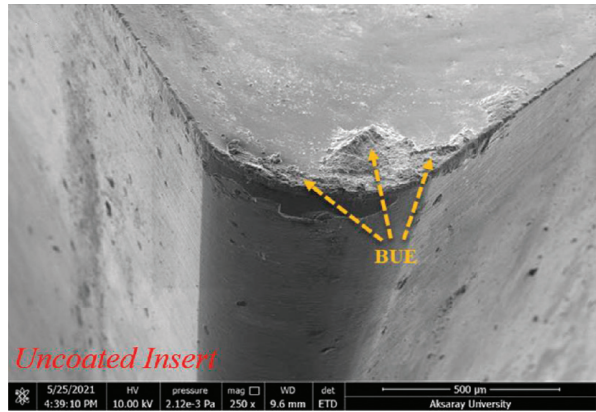

(a)

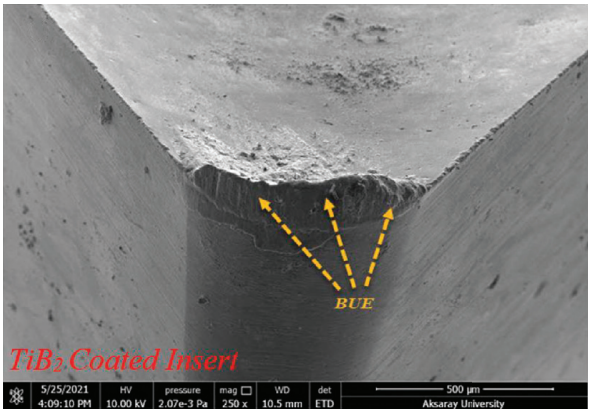

(b)

FIGURE 5: Continued. 


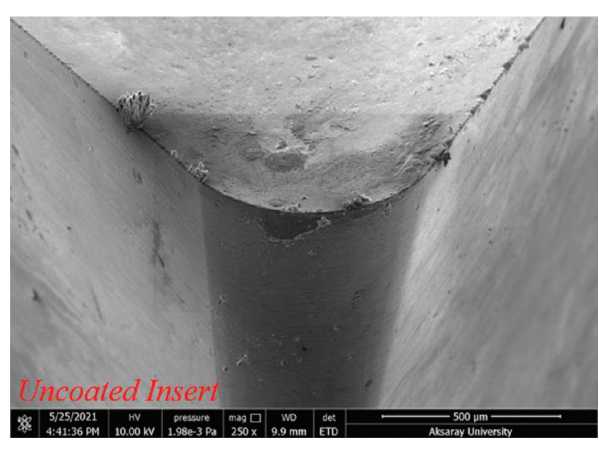

(c)

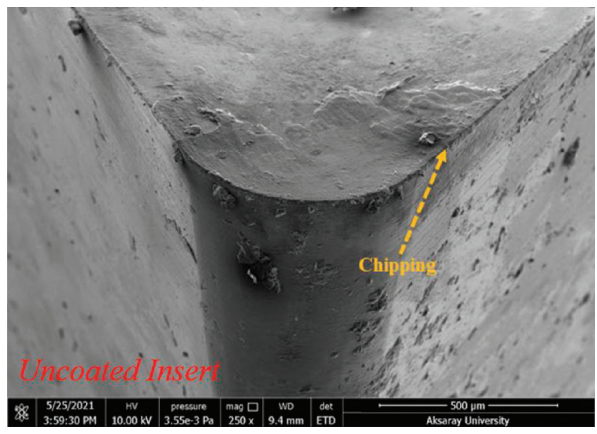

(e)

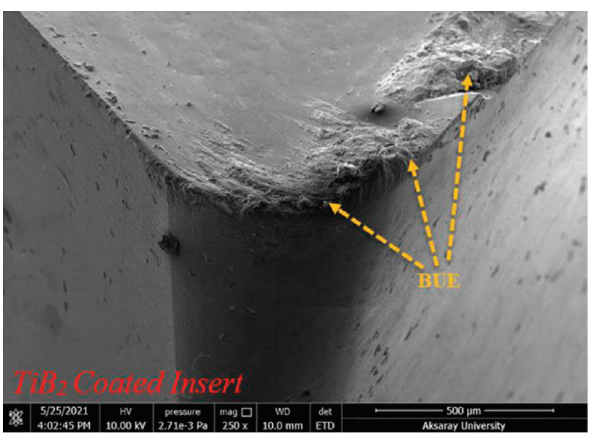

(d)

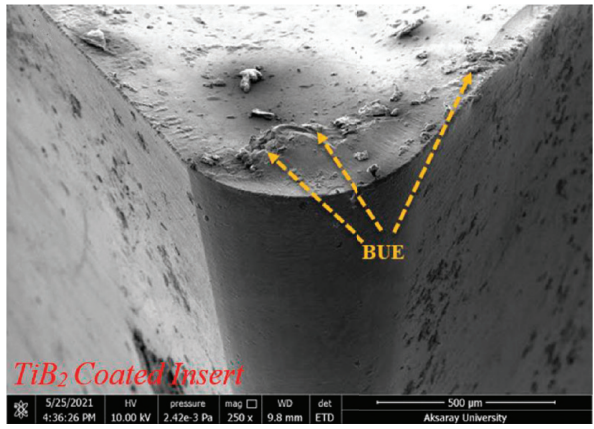

(f)

FIGURE 5: SEM images of the cutting tools.

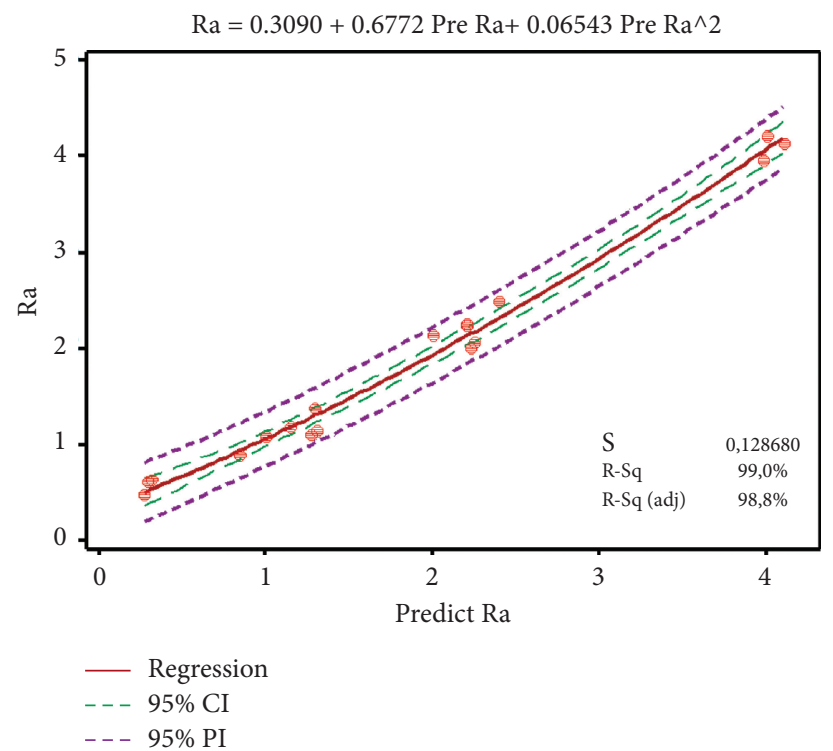

Figure 6: Comparison of actual and estimated values for Ra. 


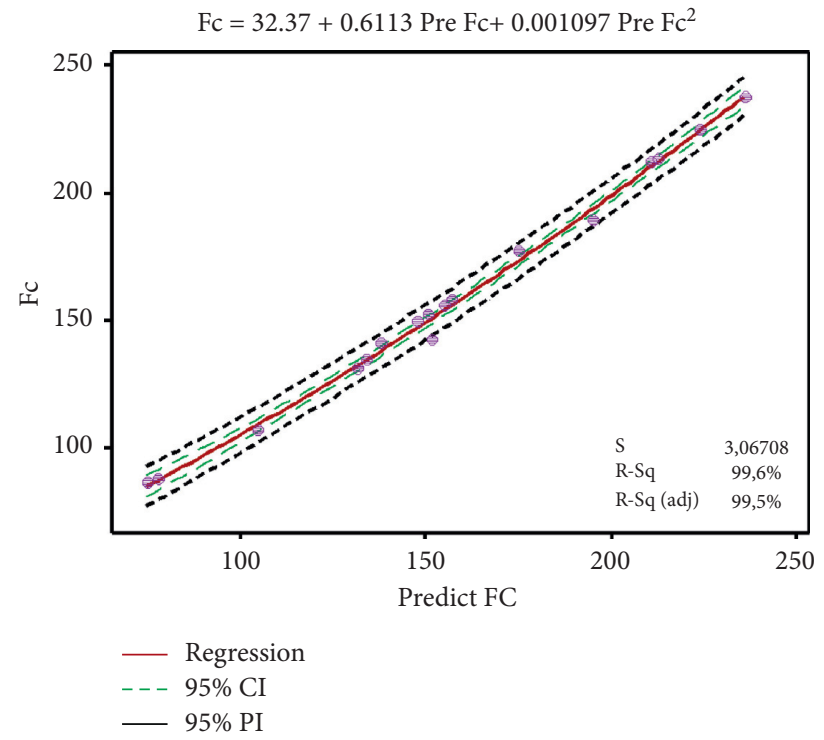

Figure 7: Comparison of actual and estimated values for Fc.

TABLE 7: Representations of the expressions in equations (8) and (9).

\begin{tabular}{lccc}
\hline $\mathrm{F} \alpha, f e$ & The $\mathrm{F}$ ratio at a 95 percent CI & $V e$ & The error variance \\
$\mathrm{A}$ & The significance level & $N$ & The total number of experiments \\
$\mathrm{Fe}$ & The degrees of freedom of error & Tdof & The total main factor degrees of freedom \\
$n_{\mathrm{eff}}$ & The effective number of replications & $R$ & The number of replications for the confirmation experiments \\
\hline
\end{tabular}

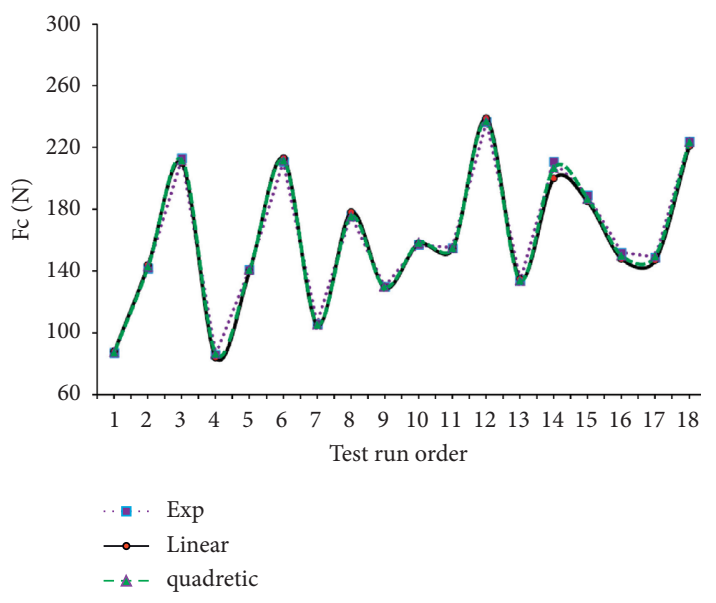

(a)

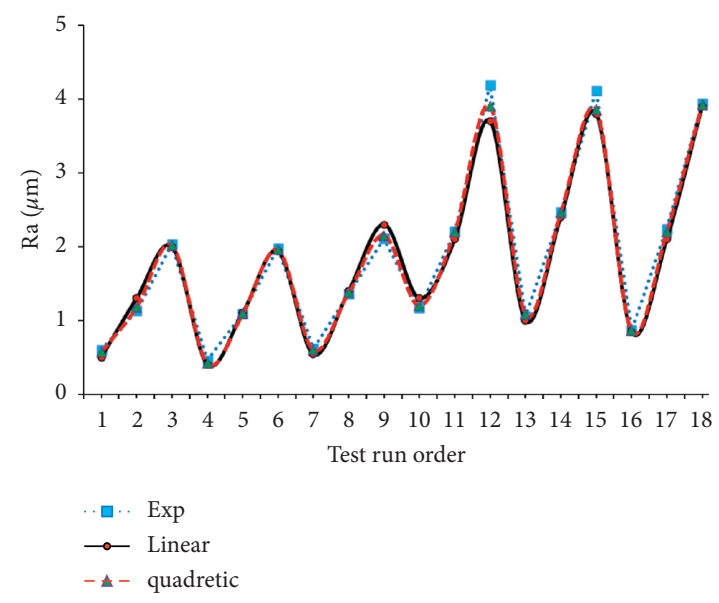

(b)

FIgURE 8: The deviations between the actual and predicted values for $\mathrm{Fc}(\mathrm{a})$ and $\mathrm{Ra}(\mathrm{b})$.

TABLE 8: The verification test results.

\begin{tabular}{|c|c|c|c|c|c|c|}
\hline \multirow{2}{*}{ Level } & \multicolumn{3}{|c|}{ Linear regression equations } & \multicolumn{3}{|c|}{ Quadratic regression equations } \\
\hline & Exp. & Pred. & Error $(\%)$ & Exp. & Pred. & Error $(\%)$ \\
\hline \multicolumn{7}{|l|}{$R a(\mu m)$} \\
\hline $\mathrm{A}_{1} \mathrm{~B}_{3} \mathrm{C}_{3} \mathrm{D}_{2}$ & 1.950 & 2.385 & 17.17 & 1.950 & 1.709 & 12.35 \\
\hline $\mathrm{A}_{2} \mathrm{~B}_{2} \mathrm{C}_{1} \mathrm{D}_{3}$ & 1.092 & 1.187 & 8.69 & 1.092 & 1.069 & 2.10 \\
\hline \multicolumn{7}{|l|}{$F c(N)$} \\
\hline $\mathrm{A}_{1} \mathrm{~B}_{3} \mathrm{C}_{3} \mathrm{D}_{2}$ & 175.07 & 179.37 & 2.49 & 175.07 & 172.31 & 1.53 \\
\hline $\mathrm{A}_{2} \mathrm{~B}_{2} \mathrm{C}_{1} \mathrm{D}_{3}$ & 162.05 & 165.54 & 2.15 & 162.05 & 160.45 & 0.98 \\
\hline
\end{tabular}


Additional turning tests were also conducted at the $\mathrm{A}_{1} \mathrm{~B}_{3} \mathrm{C}_{3} \mathrm{D}_{2}$ and $\mathrm{A}_{2} \mathrm{~B}_{2} \mathrm{C}_{1} \mathrm{D}_{3}$ levels, which are not included in the current test series. Confirmation test results performed at optimum and random levels are given in Table 8 .

As can be seen from Figure 8 and Table 8, the deviations between the real and the predicted values obtained in linear and quadratic regression models for $\mathrm{Fc}$ and $\mathrm{Ra}$ are quite minor. Many studies have reported that deviations should be less than 20 percent for the reliability of the validation experiment. [28, 29]. Consequently, the regression models for $\mathrm{Fc}$ and $\mathrm{Ra}$ with high coefficients of determination $\left(R^{2}\right)$ values give reliable results within the confidence interval.

\section{Conclusion}

In this study, the effects of cutting tool coating and cutting parameters on cutting force and surface roughness in turning AA 6061 alloy have been investigated experimentally and statistically. Some key results from the experimental and statistical study can be itemized as follows:

(i) In general, the surface roughness was observed to be decreased with the increase in cutting speed but increased depending on the increase in feed rate

(ii) In the tool wear examination, a tendency to build up (BUE) formation was observed, and it was determined that it decreased with increasing cutting speed

(iii) The optimum surface roughness and cutting force values were measured to be $0.387 \mu \mathrm{m}$ and $78.5 \mu \mathrm{m}$ as a result of the machining experiment made with the following parameters: at (a) at a cutting tool of uncoated, (b) at a cutting speed was $350 \mathrm{~m} / \mathrm{min}$, (c) at a feed rate of $0.1 \mathrm{~mm} / \mathrm{rev}$, and (d) at a depth of cut of $1 \mathrm{~mm}$

(iv) The feed rate is the most influential parameter on surface roughness and cutting force, with $64.28 \%$ and $54.9 \%$, respectively

(v) The developed mathematical models for cutting force $(\mathrm{Fc})$ and surface roughness $(\mathrm{Ra})$ present reliable results with coefficients of determination $\left(R^{2}\right)$ of $96.04 \%$ and $92.15 \%$, respectively

(vi) Validation experiments show that the optimization process is within the confidence interval at a $95 \%$ significance level

(vii) When turning AA 6061 alloy, we recommend considering sharp-edged cutting tools rather than cutting tool coating to prevent chips from sticking to the surface of the cutting insert

\section{Data Availability}

The data used to support the findings of this study are available from the corresponding author upon request or within the article.

\section{Conflicts of Interest}

The authors declare that they have no conflicts of interest.

\section{References}

[1] S. Gredig, S. Tagliaferri, M. Maciejewski, and A. Baiker, Catalysis and Automotive Pollution Control III, Elsevier, Amsterdam, Netherland, 1995.

[2] H. Demir and S. Gündüz, "The effects of aging on machinability of 6061 aluminium alloy," Materials \& Design, vol. 30, no. 5, pp. 1480-1483, 2009.

[3] E. Nas and B. Öztürk, "Optimization of surface roughness via the Taguchi method and investigation of energy consumption when milling spheroidal graphite cast iron materials," $M a$ terials Testing, vol. 60, no. 5, pp. 519-525, 2018.

[4] M. Karabatak and F. Kara, "Experimental optimization of surface roughness in hard turning of AISI D2 cold work tool steel," Journal of Polytechnic, vol. 19, no. 3, pp. 349-355, 2016.

[5] M. Akgün and H. Demir, "Estimation of surface roughness and flank wear in milling of Inconel 625 Superalloy," Surface Review and Letters, vol. 28, no. 4, Article ID 2150011, 2021.

[6] F. Kara, "Taguchi optimization of surface roughness and flank wear during the turning of DIN 1.2344 tool steel," Materials Testing, vol. 59, no. 10, pp. 903-908, 2017.

[7] T. Kivak, "Optimization of surface roughness and flank wear using the Taguchi method in milling of Hadfield steel with PVD and CVD coated inserts," Measurement, vol. 50, pp. 19-28, 2014.

[8] M. Akgün and H. Demir, "Optimization of cutting parameters affecting surface roughness in turning of inconel 625 superalloy by cryogenically treated tungsten carbide inserts," $S N$ Applied Sciences, vol. 3, p. 277, 2021.

[9] R. Işık, B. Özlü, and H. Demir, "Experimental and statistical investigation of the effect of the parameters selected in cutting process with laser st-37 material," Firat University Journal of Engineering, vol. 33, no. 1, pp. 161-171, 2021.

[10] H. Akkuş and H. Yaka, "Experimental and statistical investigation of the effect of cutting parameters on surface roughness, vibration and energy consumption in machining of titanium 6Al-4V ELI (grade 5) alloy," Measurement, vol. 167, Article ID 108465, 2021.

[11] G. Taguchi, S. Chowdhury, and Y. Wu, Taguchi's Quality Engineering Handbook, John Wiley \& Sons, Hoboken, NJ, USA, 2005.

[12] B. Rajeswari and K. S. Amirthagadeswaran, "Experimental investigation of machinability characteristics and multi-response optimization of end milling in aluminium composites using RSM based grey relational analysis," Measurement, vol. 105, pp. 78-86, 2017.

[13] A. R. Gonçalves and B. M. Silva, "Influence of copper content on 6351 aluminum alloy machinability," Procedia Manufacturing, vol. 1, pp. 683-695, 2015.

[14] M. S. Ranganath, R. S. Vipin, R. S. Mishra, and N. Prateek, "Optimization of surface roughness in CNC turning of aluminium 6061 using Taguchi techniques," International Journal of Modern Engineering Research (IJMER), vol. 5, pp. 42-50, 2015.

[15] B. Öztürk and F. Kara, "Calculation and estimation of surface roughness and energy consumption in milling of 6061 alloy," Advances in Materials Science and Engineering, vol. 2020, Article ID 5687951, 12 pages, 2020. 
[16] K. Palanikumar, "Experimental investigation and optimisation in drilling of GFRP composites," Measurement, vol. 44, no. 10, pp. 2138-2148, 2011.

[17] I. Asilturk and H. Akkus, "Determining the effect of cutting parameters on surface roughness in hard turning using the Taguchi method," Measurement, vol. 44, pp. 1697-1704, 2011.

[18] M. Akgün and H. Demir, "Optimization and finite element modelling of tool wear in milling of Inconel 625 superalloy," Politeknik Dergisi, vol. 24, no. 2, pp. 391-400, 2021.

[19] H. Gürbüz, A. Kurt, İ. Korkut, and U. Şeker, "The experimental investigation of the effects of different chip breaker forms on the cutting forces," Advanced Materials Research, vol. 23, pp. 191-194, 2007.

[20] S. Yağmur, M. K. Kaya, and U. Şeker, "Investigation of the effects of chip breaker forms applied to polycrystalline diamond (PCD) tools on cutting forces in turning AA6082 T4 alloy," Gazi Journal of Engineering Sciences, vol. 7, no. 1, pp. 51-57, 2021, https://dergipark.org.tr/tr/pub/gmbd/issue/ $62186 / 899813$

[21] H. Demir, S. Gündüz, and M. A. Erden, "Influence of the heat treatment on the microstructure and machinability of AISI H13 hot work tool steel," International Journal of Advanced Manufacturing Technology, vol. 95, no. 5, pp. 2951-2958, 2018.

[22] B. Özlü, "Investigation of the effect of cutting parameters on cutting force, surface roughness and chip shape in turning of Sleipner cold work tool steel," Journal of the Faculty of Engineering and Architecture of Gazi University, vol. 36, no. 3, pp. 1241-1251, 2021.

[23] I. Ciftci and H. Gökçe, "Optimization of cutting tool and cutting parameters in machining of molybdenum alloys through the Taguchi Method," Journal of the Faculty of Engineering and Architecture of Gazi University, vol. 34, no. 1, pp. 201-213, 2019.

[24] G. Boothroyd and W. A. Knight, Fundamentals of Machining and Machine Tools", Taylor \& Francis, New York, NY, USA, 3rd edition, 2006.

[25] M. E. Korkmaz, N. Yaşar, and M. Günay, "Numerical and experimental investigation of cutting forces in turning of Nimonic 80A superalloy," Engineering Science and Technology, an International Journal, vol. 23, no. 3, pp. 664-673, 2020.

[26] I. Ciftci, "Machining of austenitic stainless steels using CVD multi-layer coated cemented carbide tools," Tribology International, vol. 39, no. 6, pp. 565-569, 2006.

[27] E. M. Trent, Metal Cutting, Butterworths Press, London, UK, 1989.

[28] F. Kara and B. Öztürk, "Comparison and optimization of PVD and CVD method on surface roughness and flank wear in hard-machining of DIN 1.2738 mold steel," Sensor Review, vol. 39, no. 1, pp. 24-33, 2019.

[29] P. J. Ross, Taguchi Techniques for Quality Engineering, McGraw-Hill International Book Company, New York, NY, USA, 1996. 